\title{
Lesion Restenosis Indicator
}

National Cancer Institute

\section{Source}

National Cancer Institute. Lesion Restenosis Indicator. NCI Thesaurus. Code C116147.

An indication as to whether there is re-narrowing of a lesion site following treatment of a prior stenosis, to a diameter stenosis of greater than $50 \%$ at the previously treated lesion site. 